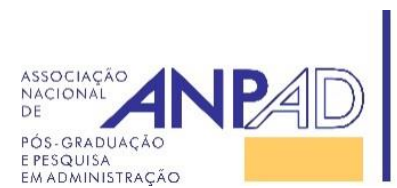

Disponível em

http://www.anpad.org.br/rac

RAC, Rio de Janeiro, v. 21, n. 4,

pp. 585-604, Julho/Agosto, 2017

http://dx.doi.org/10.1590/1982-7849rac2017170066

(cc) EY

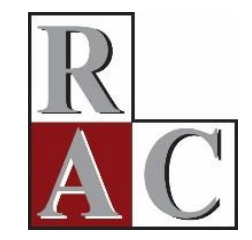

Casos para Ensino:

\title{
Exportar é o que Importa! O Caso de uma Associação Brasileira de Fabricantes de Móveis
}

Export Matters! The Case of a Brazilian Furniture Manufacturing Association

Marcelo André Machado ${ }^{1}$

Ivan Lapuente Garrido ${ }^{1}$

Universidade do Vale do Rio dos Sinos ${ }^{1}$

Editora Associada: Profa. Anete Alberton. 


\section{Introdução}

Após alguns anos de forte atuação voltada ao mercado doméstico, Vicente Marquiz, presidente da Associação de Indústrias Moveleiras do Brasil (AIMOB), percebeu a necessidade de reforçar outros horizontes de atuação da entidade que preside. Os resultados auspiciosos obtidos no Brasil, pelas 17 pequenas e médias fabricantes de móveis associadas da entidade, nos últimos anos, começam a desgastar os benefícios percebidos de atuação em rede.

Surge dentro da associação um sentimento de que algumas moveleiras são mais beneficiadas que outras pelas iniciativas da AIMOB. Essa percepção ganha força a partir da experiência positiva de algumas empresas do grupo na atividade de exportação. Assim, os associados demandam um papel mais protagonista da entidade na promoção de um processo estruturado e continuado de busca de mercados no exterior para todas as participantes e, ainda, de preparação das empresas associadas que ainda não exportam.

As questões que emergem da preocupação dos associados e da presidência da entidade, ligadas à própria sobrevivência da AIMOB, são: Por onde a AIMOB deveria começar para promover a exportação por parte de todos seus associados? Quais seriam as prioridades nesse processo? Qual deveria ser o plano de ação da entidade?

\section{A Indústria Moveleira no Brasil}

A indústria de móveis é considerada um setor tradicional da economia brasileira, pois apresenta características como o reduzido dinamismo tecnológico, o uso de mão de obra intensiva e a utilização, em grande parte, de materiais de origem animal ou vegetal (Rosa, Correa, Lemos, \& Barroso, 2007). Esses elementos provocam considerável competição entre os fabricantes de mobiliário, tanto para aqueles que competem em uma faixa superior de preços como para os que trabalham com móveis mais econômicos.

Contudo, mesmo não havendo um forte dinamismo tecnológico, cabe ressaltar o papel do design que, no caso de móveis, não se restringe aos aspectos estéticos, mas também à funcionalidade dos produtos. Ainda que o design seja um atributo liderado por empresas italianas, há um claro espaço de oportunidade para empresas brasileiras, pois não existem obstáculos expressivos em competir por design em virtude da relativa facilidade de imitação (Sindicato das Indústrias do Mobiliário de Bento Gonçalves [SINDMÓVEIS], L. B. Ramos, comunicação pessoal, 10 de agosto de 2013).

Dessa forma, o design e as certificações de qualidade e padronização internacionais têm sido os pontos mais vulneráveis da indústria brasileira para a competição internacional, já que essa se encontra relativamente distante, nesses quesitos, dos principais polos de desenvolvimento mundial de tecnologia moveleira: Europa e Ásia. Porém, em países desenvolvidos, a produção de móveis é menos verticalizada. Já no Brasil, nota-se maior verticalização das indústrias moveleiras, situadas em clusters moveleiros.

A principal consequência das limitações identificadas na indústria de móveis no Brasil é a escala reduzida de produção das empresas, inclusive nas líderes. Assim, nota-se a ausência de barreiras à entrada de competidores decorrentes de economias de escala, o que seria comum em empresas industriais modernas. Ao se analisar o segmento de móveis de madeira, em especial, percebe-se que se trata de uma indústria conservadora da atual estrutura produtiva de móveis (SINDMÓVEIS, L. B. Ramos, comunicação pessoal, 10 de agosto de 2013).

No Brasil a indústria de móveis pode ser classificada de acordo com a matéria prima (madeira ou metal) ou de acordo com a categoria de uso: móveis residenciais, para escritórios e institucionais (para hospitais, escolas, restaurantes, hotéis e assemelhados). Os fabricantes de móveis de madeira 
representam 91\% dos estabelecimentos no Brasil, incluídas aqui as indústrias que utilizam madeira maciça (pinus e eucalipto) ou painéis de madeira reconstituída (MDF ou aglomerado) (Rosa et al., 2007).

O Brasil era o quinto maior fabricante de móveis do mundo em 2012, contando com 16,5 mil indústrias de móveis, que empregavam aproximadamente 307 mil pessoas, de acordo com o SINDMÓVEIS (L. B. Ramos, comunicação pessoal, 10 de agosto de 2013). Apesar de estar presente em todos os Estados da Federação, a indústria moveleira encontra-se, predominantemente, nas regiões Sul e Sudeste que representam $77 \%$ da produção nacional de móveis. No Rio Grande do Sul, a cidade de Bento Gonçalves foi responsável, sozinha, por 30\% da produção de móveis do país. No ano de 2011 o faturamento total do setor foi de R \$ 35 bilhões, contudo as exportações representaram apenas US\$ 743 milhões (Agência Brasileira de Promoção de Exportações e Investimento [APEX], 2012; SINDMÓVEIS, L. B. Ramos, comunicação pessoal, 10 de agosto de 2013).

De acordo com a APEX (2012, p. 5),

a Região Sul é a maior exportadora de móveis do Brasil, ainda que sua participação nas exportações totais de mobiliário tenha se reduzido, em média, mais de 6\% ao ano, entre 2006 e 2011. O movimento de queda também se repetiu nas outras regiões, especialmente no Nordeste.

\section{Mercado Mundial de Móveis}

O consumo de móveis no mundo vem crescendo nos últimos anos, principalmente nos mercados emergentes como os países do BRICS, conforme Tabela 1. Contudo, os maiores importadores de móveis são os países desenvolvidos, sendo os EUA o maior importador de móveis, com uma demanda que representa 25\% das importações mundiais. O México e o Panamá são os únicos países latino-americanos a figurarem entre os 25 maiores importadores (SINDMÓVEIS, L. B. Ramos, comunicação pessoal, 10 de agosto de 2013). O Brasil é o $39^{\circ}$ maior importador, com um montante de US\$ 320 milhões em 2014, conforme dados do Ministério do Desenvolvimento, Indústria e Comércio Exterior (MDIC, 2014).

Tabela 1

Principais Países Consumidores de Móveis

\begin{tabular}{cccccccc}
\hline Países & $\mathbf{2 0 1 2}$ & $\mathbf{2 0 1 3}$ & $\mathbf{2 0 1 4} *$ & $\mathbf{2 0 1 5 *}$ & $\mathbf{2 0 1 6} *$ & $\mathbf{2 0 1 7} *$ & $\begin{array}{c}\text { Crescimento Anual Médio } \\
\text { (2012-2017)* }\end{array}$ \\
\hline EUA & 137.487 & 139.594 & 142.558 & 145.828 & 148.861 & 152.334 & $2,07 \%$ \\
\hline Alemanha & 45.051 & 44.902 & 44.679 & 44.769 & 44.894 & 45.069 & $0,01 \%$ \\
\hline Brasil & 29.081 & 30.243 & 32.037 & 33.921 & 35.822 & 37.614 & $5,28 \%$ \\
\hline China & 23.366 & 25.641 & 27.720 & 30.164 & 32.668 & 35.237 & $8,56 \%$ \\
\hline Itália & 31.926 & 31.274 & 31.102 & 31.116 & 31.179 & 31.319 & $-0,38 \%$ \\
\hline Reino Unido & 25.252 & 25.351 & 25.637 & 25.895 & 26.287 & 26.709 & $1,13 \%$ \\
\hline Rússia & 20.066 & 21.115 & 22.912 & 24.130 & 25.286 & 26.369 & $5,61 \%$ \\
\hline França & 22.124 & 22.030 & 21.904 & 21.912 & 22.003 & 21.927 & $-0,18 \%$ \\
\hline
\end{tabular}

Nota. Valores em milhões de dólares (US\$ mi). Panorama consumo e produção de móveis, Projeto Orchestra Brasil. Fonte: SINDMÓVEIS (L. B. Ramos, comunicação pessoal, 10 de agosto de 2013).

* Previsão.

A produção mundial de móveis está concentrada na Europa, América do Norte e Ásia. A China é o maior produtor com US\$ 140 bilhões em 2012, seguida pelos EUA e pela Alemanha. O Brasil, quinto 
maior fabricante de móveis do mundo, teve uma produção de US\$ 20 bilhões em 2012 (SINDMÓVEIS, L. B. Ramos, comunicação pessoal, 10 de agosto de 2013).

Em uma análise mais específica da produção e do consumo mundial de móveis, nota-se que os países europeus estão entre os maiores produtores e exportadores de móveis de alto valor agregado, com destaque para a Itália e a Alemanha, onde os fabricantes dão ênfase ao design e a materiais inovadores. No entanto, esses países são grandes importadores de móveis retilíneos e seriados de menor valor agregado, principalmente de mercados emergentes como a China (APEX, 2012).

Para os exportadores brasileiros de móveis voltados mais à decoração e ao design, os mercados europeu e norte americano têm representado uma grande oportunidade, pois há crescente valorização de vários elementos conceituais embutidos nas propostas dos fabricantes para o segmento high end. Já no que diz respeito aos fabricantes de móveis brasileiros posicionados para o mercado middle e low end, as vantagens para os exportadores nacionais aparecem apenas quando os compradores buscam pequenos pedidos ou quando a taxa de câmbio do real para o dólar está desvalorizada. Do contrário, a vantagem competitiva recai sobre os móveis chineses, principalmente pela economia de escala que a indústria moveleira chinesa possui (SINDMÓVEIS, L. B. Ramos, comunicação pessoal, 10 de agosto de 2013).

Por outro lado, destacam-se iniciativas de alguns fabricantes brasileiros que buscam avançar na cadeia de valor no exterior, inaugurando lojas próprias ou franqueadas em vários países. Essa estratégia tem permitido às exportadoras brasileiras de móveis comunicarem mais adequadamente sua proposta de valor e, ao mesmo tempo, conseguirem ter maior controle sobre o canal de comercialização de seus produtos.

\section{A AIMOB}

A AIMOB é uma entidade composta por 17 fábricas de pequeno e médio porte (PME) que se dedicam a produzir diferentes tipos de móveis, tais como: estofados, móveis para livings e dormitórios, cozinhas e móveis para escritórios. Ela está situada em um importante polo moveleiro do estado do Rio Grande do Sul. Seus dirigentes são todos empresários da indústria moveleira, pois a entidade mantém uma estrutura organizacional enxuta com apenas um gerente e dois assistentes contratados.

Criada no ano de 2000, a AIMOB teve como finalidade inicial aumentar o poder de barganha dos associados para a compra de insumos necessários à produção de móveis. Como isoladamente as empresas tinham dificuldade de negociar lotes mais econômicos de matérias-primas, montar uma rede de compras parecia uma solução natural para os gestores das 08 PMEs fundadoras da AIMOB.

Contudo, logo se percebeu que outras atividades poderiam ser desempenhadas pela associação e que reforçariam os benefícios da atuação colaborativa. Uma dessas atividades foi a promoção dos móveis da entidade, tanto no Brasil como no exterior. Logo, em 2002, é inaugurado um showroom na Serra Gaúcha em um prédio alugado onde os associados faziam a composição de ambientes a partir da combinação dos móveis fabricados do grupo. Nesse ponto, a AIMOB já contava com 12 associados.

Com a identificação do apoio dirigido pelo governo brasileiro apenas à associação de exportadores, através da Agência Brasileira de Apoio às Exportações e Investimentos (APEX), em 2003 a entidade consegue suporte financeiro para um showroom em Miami-EUA, porém apenas uma pequena parte dos associados estava pronta e disposta a expor seus produtos lá.

Em 2015, já com 17 associados, a entidade faz uma reestruturação e opta pelo fechamento dos dois showrooms. No mercado doméstico, percebiam-se sinais de desaquecimento no setor moveleiro, após 08 anos de forte demanda interna. Já no mercado externo, após 10 anos de valorização cambial que tiraram competitividade das exportações brasileiras de móveis, esse canal de comercialização também perdeu o sentido. É justamente a partir dessa reestruturação que começa a emergir o debate sobre o 
futuro da AIMOB: o que a associação poderia fazer para ampliar as vendas, no Brasil e no exterior, por parte de seus associados?

Do ponto de vista financeiro, é importante verificar que a associação tem suas receitas oriundas das mensalidades pagas pelas empresas participantes, de acordo com o faturamento de cada associado. Esse recurso cobre as despesas operacionais e uma parte compõe um fundo que é a reserva técnica para iniciativas discutidas e aprovadas pelos membros em reunião. A Tabela 2 apresenta a entidade e seus números.

Tabela 2

\section{A AIMOB em Números}

\begin{tabular}{lc|}
\hline Número de empresas associadas: & 17 \\
\hline Capacidade de produção do grupo: & 150.000 peças/mês \\
\hline Faturamento anual do grupo: & US\$ 130 milhões \\
\hline Faturamento de exportação anual: & US\$ 17,5 milhões \\
\hline Número de colaboradores dos associados: & 1.100 empregados \\
\hline
\end{tabular}

Nota. Fonte: SINDMÓVEIS (L. B. Ramos, comunicação pessoal, 10 de agosto de 2013).

\section{A reunião na AIMOB}

O presidente da AIMOB entende a urgência e relevância que o assunto demanda, principalmente por parte das empresas do grupo que ainda não exportam. Assim, a direção da associação convocou uma reunião para deliberar sobre possíveis iniciativas e a necessidade de informações que pudessem subsidiar as ações voltadas à exportação nas empresas associadas.

Tomam parte da reunião os seguintes componentes da direção da AIMOB, além dos gestores das indústrias moveleiras associadas: o presidente da Associação, Vicente Marquiz, proprietário de uma indústria de móveis para escritório; o vice-presidente, Otelo Armindo Nunes, proprietário de uma indústria de estofados; o diretor de comércio exterior, Raul Cauduro, proprietário de uma indústria de móveis ready to assemble (RTA), que exporta há mais de 15 anos; o assistente de comércio exterior, Alceu Flowers, funcionário da associação, com formação e experiência em comércio exterior; o diretor de compras, Eugênio Simeone, proprietário de uma indústria de móveis de madeira; a diretora de marketing, Salete Kirtz, proprietária de uma indústria de móveis de pinus, que exporta praticamente toda a produção, há mais de 10 anos; o diretor jurídico, Roque Pleyn, proprietário de uma indústria de móveis para cozinhas; e o diretor financeiro, Carlos França, proprietário de uma indústria de estofados em couro, que exporta há mais de 15 anos.

A reunião foi realizada na sede da AIMOB e percebia-se, desde o início, relativa ansiedade por parte dos associados presentes. Não era para menos. Considerando-se a expectativa que se formara no grupo pela experiência lucrativa e bem sucedida na exportação de algumas empresas da entidade, a possibilidade de inserção dos móveis de outros fabricantes da associação em novos mercados no exterior era muito aguardada. Para o presidente da entidade, assim como para os demais integrantes da associação, existia uma crença de que o futuro e o sucesso de suas empresas, juntamente com a AIMOB, estavam vinculados diretamente ao desenvolvimento das atividades de exportação.

É nesse clima de expectativa que Vicente Marquiz, presidente da AIMOB, abriu a reunião resgatando os elementos que levaram à formação da associação:

"Somos, hoje, uma associação que integra 17 fabricantes de móveis. Quando constituímos a associação, nosso objetivo inicial era aumentar o poder de barganha na compra de insumos, pela sinergia dos associados. Acreditávamos que ganharíamos maior importância junto aos nossos fornecedores e conseguiríamos, assim, melhores condições comerciais para os associados. Também, poderíamos reduzir 
nossos custos com a execução de algumas atividades conjuntas, como a criação de uma loja da associação, iniciativa que mantivemos até o ano passado, mas resolvemos desativá-la e nos concentrarmos de forma mais efetiva em outras atividades. Mas é chegado o momento de buscar novas oportunidades para todos associados."

Raul Cauduro, diretor de comércio exterior da entidade, pede imediatamente a palavra e enfatiza que algumas empresas do grupo já exportam, como é o caso da sua própria empresa. Porém, é visível que o volume ainda é pequeno em relação aos objetivos dos associados, não chegando a $15 \%$ do faturamento total do grupo de empresas. Além disso, várias empresas que compõem a AIMOB não têm nenhuma experiência em comércio exterior, ou seja, nunca exportaram.

Para o diretor financeiro, Carlos França, não há consenso entre os associados quanto ao percentual do faturamento das empresas que deveria ser proveniente das exportações. Entretanto, a meta de 30\% do faturamento total parece emergir como uma meta aceita pelos gestores de todas as empresas que integram a entidade. Esse valor traz grandes desafios à entidade mas, ao mesmo tempo, grandes oportunidades de engajamento de novos associados.

Já o diretor jurídico da AIMOB, Roque Pleyn, proprietário de uma empresa que já exporta há algum tempo, esclarece que é necessário, antes de mais nada, identificar as motivações para que uma empresa inicie a exportação. $\mathrm{O}$ gestor preocupa-se em explicar aos demais participantes da reunião, principalmente de empresas que ainda não exportam, que explorar o mercado externo para móveis requer certo grau de investimento e comprometimento de recursos, financeiros e humanos, nessa estratégia. Além disso, os resultados não são imediatos, mas, por outro lado, como ele mesmo explica, há vários ganhos diretos e indiretos com a exportação.

Um primeiro e talvez o mais importante benefício da exportação, segundo o diretor, provém do fato de que a exportação pode reduzir as oscilações no faturamento da empresa provocadas pelo frequente stop and go da economia doméstica, o que muitas vezes não permite à empresa fazer um planejamento de longo prazo. Outro ganho é a possibilidade que a exportação tem de gerar ativos em moeda forte, dólares norte-americanos, para fazer frente à necessidade de pagamento das importações de insumos, cotados também nessa moeda. Assim, segundo o gestor, a empresa que exporta teria uma espécie de hedge natural ou proteção contra os efeitos da variação cambial na compra de insumos importados.

Ratificando as motivações mencionadas pelo diretor jurídico, o presidente da AIMOB, Vicente Marquiz, salienta que a associação formalizou um pedido de apoio à internacionalização para a APEX, e comenta:

"Isso tem dado resultados positivos. Dentro do apoio aprovado pela APEX à AIMOB, temos recursos para a participação em feiras internacionais, para folheteria de divulgação externa da associação, para o desenvolvimento de design e para a criação de marcas brasileiras. Temos, ainda, recursos para trazer ao Brasil potenciais importadores estrangeiros."

O vice-presidente da associação, Otelo Armindo Nunes, apressa-se em complementar que todos esses recursos da APEX são oferecidos a fundo perdido, mas com contrapartida de $50 \%$ dos valores por parte dos associados que usufruírem dos mesmos. É nesse momento que intervém, de forma mais apreensiva, Carlos França, proprietário de uma empresa que ainda não exporta. Segundo ele, apesar das sinergias que no passado ajudaram a AIMOB a se consolidar como associação, existem diferenças no perfil das empresas e dos produtos por elas fabricados que atrapalham a atuação conjunta no mercado externo.

As diferenças são percebidas em vários aspectos, como os tipos de produtos. As empresas da AIMOB fabricam os mais diversos produtos para o segmento moveleiro, por exemplo: estofados, cozinhas, salas de jantar, móveis para livings, dormitórios e móveis para escritórios. Além disso, algumas empresas trabalham com móveis de madeira, algumas com MDF, outras com aglomerado e, ainda, algumas com ferro e couro. 
Outro problema é a grande diferença no posicionamento competitivo e na segmentação de mercados. Os produtos das empresas do grupo atendem a diferentes públicos-alvo, desde produtos mais econômicos para consumidores de baixa renda ou mercado low end (classes $\mathrm{C}$ e D) até produtos diferenciados para consumidores de alta renda ou high end (classes A e B).

Já no que diz respeito à capacidade e tecnologia produtiva, há uma grande diferença entre os associados. Algumas empresas do grupo têm limitações de produção para atender a grandes pedidos e, por vezes, não possuem tecnologia ou qualidade que lhes permita fazer acabamentos mais sofisticados nos produtos, principalmente as que trabalham com aglomerados. Por outro lado, há moveleiras do grupo com excelente capacidade produtiva e tecnológica.

Outro ponto que merece atenção é o pouco fôlego financeiro por parte de algumas empresas associadas para financiar suas atividades no mercado doméstico. No caso da exportação, sabe-se que essa atividade requer um investimento cujo retorno não se dá no curto prazo. O contraponto dessa situação se dá na medida em que outras empresas da AIMOB contam com excelente capacidade financeira para alavancar investimentos em projetos de exportação.

Após a intervenção do diretor financeiro, o presidente da associação, Vicente Marquiz, fez um depoimento que ajudou a elucidar um pouco mais os desafios implícitos no processo de internacionalização das empresas da AIMOB. Segundo ele, já houve uma tentativa da associação de ingressar no mercado norte-americano. Essa iniciativa se deu por meio da criação de um Centro de Distribuição (CD) em Miami, EUA, e que funcionava como um showroom da AIMOB, no qual todos os associados podiam expor seus produtos para comercialização naquele mercado. $\mathrm{O}$ problema destacado pelo presidente estava no fato de que o agente designado para operar o CD em Miami tinha larga experiência na comercialização de móveis mais populares ou low end. Assim, os produtos high end, mais diferenciados e destinados a consumidores igualmente exigentes, acabavam não recebendo um tratamento adequado quanto ao esforço de vendas naquele mercado.

Nesse momento, muitos dos associados presentes na reunião começaram a questionar sobre quais ações já estariam em andamento, em termos de promoção voltada à exportação. Assim, o presidente passa imediatamente a palavra para Salete Kirtz, diretora de marketing da AIMOB, que inicia uma apresentação das ações desenvolvidas para a promoção dos produtos dos associados no mercado internacional.

Expressando certo constrangimento, a diretora Salete afirma que várias ações estão em curso, mas muita coisa precisa ser feita. Ela explica que ainda não há uma homepage da associação e que os websites das empresas associadas são desenvolvidos de maneira independente, ou seja, cada empresa decide como fazer suas páginas na web. Diz, também, que pouco material promocional foi desenvolvido até agora, existindo somente um fôlder trilíngue apresentando a associação e seus associados, que foi feito há mais de dois anos. O mesmo ainda não teria sido atualizado, pois a gestora aguarda a posição da diretoria para desenvolver novos materiais.

Quanto às feiras internacionais, a executiva explica que aproximadamente a metade dos associados tem participado de algumas feiras internacionais de móveis, seguindo os calendários das principais feiras sugeridos pela APEX ou pelo Sindicato da Indústria Moveleira (SINDMÓVEIS). Os critérios de participação nas feiras, como expositor ou visitante, são estabelecidos por cada um dos associados que desenvolvem individualmente seus materiais promocionais. A associação encarrega-se apenas de organizar grupos para a ida à feira e, também, de auxiliar com o envio de amostras e outros materiais promocionais necessários. No entanto, a diretora de marketing comenta que ainda não há nenhuma pesquisa sobre a participação nas feiras, no que diz respeito aos resultados em volume de negócios de exportação gerados a partir desses eventos.

Para Salete Kirtz, mesmo a feira sendo uma importante ferramenta de promoção em mercados internacionais e que precisa de mais investimentos, há outras ações anteriores à feira com as quais os associados deveriam se preocupar. Dois exemplos disso são, segundo ela, a falta de fôlderes das 
empresas associadas, em três idiomas, mostrando seus produtos e especificações, e a precariedade das homepages de alguns associados, conforme Tabela 3.

Tabela 3

Avaliação das Homepages e Fôlderes dos Associados da AIMOB

\begin{tabular}{lcc}
\hline Análise das homepages & SIM & NÃO \\
\hline Possui homepage? & 10 & 7 \\
Em três idiomas? & 6 & 11 \\
Apresenta histórico da empresa? & 10 & 7 \\
Apresenta a AIMOB? & 6 & 11 \\
Possui fotos dos produtos? & 11 & 6 \\
Especificações (medidas e matérias primas)? & 12 & 5 \\
Traz informações sobre tecnologia fabril? & 5 & 12 \\
Traz a cubagem dos produtos? & 13 & 4 \\
\hline Análise dos fôlderes & SIM & NÃO \\
\hline Possui fôlderes? & 12 & 5 \\
Em três idiomas? & 6 & 11 \\
Apresenta histórico da empresa? & 5 & 12 \\
Apresenta a AIMOB? & 4 & 13 \\
Possui fotos dos produtos? & 15 & 2 \\
Especificações (medidas e matérias primas)? & 13 & 4 \\
Traz informações sobre tecnologia fabril? & 5 & 12 \\
Traz a cubagem dos produtos? & 13 & 4 \\
\hline
\end{tabular}

Nota. Fonte: SINDMÓVEIS (L. B. Ramos, comunicação pessoal, 10 de agosto de 2013).

A diretora de marketing finalizou sua intervenção destacando que a larga maioria das empresas associadas não explora suas marcas, a origem do móvel (country of origin) e o fato de pertencerem a uma associação de fabricantes de móveis de uma região do Brasil com notória tradição e experiência na produção de móveis.

Nesse momento, o presidente da AIMOB convida o assistente de comércio exterior da entidade, Alceu Flowers, para apresentar aos participantes da reunião um quadro (Tabela 4) com a síntese dos dados gerais sobre as empresas da associação, para que se pudesse iniciar a discussão sobre o projeto de expansão internacional dos associados com o apoio da AIMOB. O quadro foi elaborado a partir de uma recente pesquisa solicitada pelo diretor de comércio exterior. Tinha o objetivo de fazer um levantamento preliminar sobre o potencial de internacionalização de cada uma das 17 empresas associadas. 
Tabela 4

Análise do Potencial de Internacionalização dos Associados da AIMOB

\begin{tabular}{|c|c|c|c|c|c|c|}
\hline $\mathbf{A}^{\mathbf{1}}$ & PRODUTOS & POSIC. ${ }^{2}$ & MERCADOS & $\$ \$^{3}$ & CERT. $^{4}$ & POTENCIAL \\
\hline 01 & $\begin{array}{l}\text { Estofados em tecido e } \\
\text { couro, poltronas e mesas }\end{array}$ & $\begin{array}{l}\text { Médio e Médio } \\
\quad \text { Alto }\end{array}$ & $\begin{array}{l}\text { EUA, América } \\
\text { Central, Portugal e } \\
\text { Espanha }\end{array}$ & Sim & $\begin{array}{l}\text { Sim } \\
\text { ISO }\end{array}$ & $\begin{array}{l}\text { Alto. Potencial de volume de } \\
\text { produção e boa capacidade } \\
\text { financeira. Expo=5\%. }\end{array}$ \\
\hline 02 & Estofados em tecido & Médio e Baixo & América Central & Sim & Não & $\begin{array}{l}\text { Baixo. Aparente dificuldade } \\
\text { financeira e produtiva. } \text { Expo=8\%. }\end{array}$ \\
\hline $\mathbf{0 3}$ & $\begin{array}{l}\text { Estofados em tecido e } \\
\text { couro sintético }\end{array}$ & Médio & Não exporta & Não & Não & $\begin{array}{l}\text { Médio. Fábrica bem estruturada. } \\
\text { Expo }=0 \% \text {. }\end{array}$ \\
\hline 04 & $\begin{array}{l}\text { Estofados e poltronas } \\
\text { em tecido e couro }\end{array}$ & $\begin{array}{l}\text { Alto e Médio } \\
\quad \text { alto }\end{array}$ & $\begin{array}{l}\text { EUA e América } \\
\text { Central }\end{array}$ & Sim & $\begin{array}{l}\text { Sim } \\
\text { ISO }\end{array}$ & $\begin{array}{l}\text { Alto. Fábrica e produtos de alta } \\
\text { qualidade. Muito boa capacidade } \\
\text { financeira e produtiva. Expo=10\%. }\end{array}$ \\
\hline 05 & Estofados em tecido & Médio e Baixo & $\begin{array}{l}\text { EUA, América } \\
\text { Central, Chile, } \\
\text { França e África }\end{array}$ & Sim & $\begin{array}{l}\text { Sim } \\
\text { ISO }\end{array}$ & $\begin{array}{l}\text { Médio. Apresenta limitações } \\
\text { produtivas e financeiras. Expo=5\%. }\end{array}$ \\
\hline 06 & Estofados em tecido & Médio & Não exporta & Não & Não & $\begin{array}{l}\text { Baixo. Problemas de capacidade de } \\
\text { produção e financeira. Expo=0\%. }\end{array}$ \\
\hline 07 & $\begin{array}{l}\text { Estofados em tecido e } \\
\text { courino }\end{array}$ & Baixo & América Central & Sim & Não & $\begin{array}{l}\text { Baixo. Problemas de qualidade fabri } \\
\text { e capacidade financeira. Expo=7\%. }\end{array}$ \\
\hline 08 & $\begin{array}{l}\text { Estofados em courino e } \\
\text { tecido }\end{array}$ & Baixo & $\begin{array}{l}\text { América Central e } \\
\text { África }\end{array}$ & Sim & Não & $\begin{array}{l}\text { Baixo. Empresa com problemas } \\
\text { financeiros e qualidade fabril. } \\
\text { Expo }=5 \% \text {. }\end{array}$ \\
\hline 09 & $\begin{array}{l}\text { Móveis de escritório e } \\
\text { home theaters }\end{array}$ & $\begin{array}{l}\text { Alto e Médio } \\
\text { Alto }\end{array}$ & Chile & Sim & Não & $\begin{array}{l}\text { Alto. Excelente qualidade, } \\
\text { capacidade fabril, tecnológica e } \\
\text { financeira. Expo=5\%. }\end{array}$ \\
\hline 10 & Móveis em pinus & Médio e Baixo & Inglaterra e Canadá & Sim & $\begin{array}{l}\text { Sim } \\
\text { ISO }\end{array}$ & $\begin{array}{l}\text { Médio. Boa capacidade produtiva, } \\
\text { mas baixa capacidade financeira. } \\
\text { Expo=8\%. }\end{array}$ \\
\hline 11 & $\begin{array}{l}\text { Salas de jantar e } \\
\text { complementos }\end{array}$ & $\begin{array}{l}\text { Médio e Médio } \\
\text { Alto }\end{array}$ & América Central & Sim & Não & $\begin{array}{l}\text { Alta. Boa capacidade produtiva e } \\
\text { produtos de muito boa qualidade. } \\
\text { Expo }=10 \% \text {. }\end{array}$ \\
\hline 12 & $\begin{array}{l}\text { Produtos de decoração } \\
\text { em mármore }\end{array}$ & Alto & Não exporta & Não & Não & $\begin{array}{l}\text { Baixo. Produto de alto valor } \\
\text { agregado, mas de difícil penetração. } \\
\text { Expo }=0 \% \text {. }\end{array}$ \\
\hline 13 & $\begin{array}{l}\text { Racks, estantes e } \\
\text { dormitórios }\end{array}$ & Baixo & 21 países & Sim & Não & $\begin{array}{l}\text { Alto. Boa capacidade fabril e } \\
\text { financeira. Expo }=15 \% \text {. }\end{array}$ \\
\hline 14 & Lustres e luminárias & $\begin{array}{l}\text { Médio e Médio } \\
\text { alto }\end{array}$ & Não exporta & Não & Não & $\begin{array}{l}\text { Baixo. Potencial para venda casada } \\
\text { com outros produtos. Expo }=0 \% \text {. }\end{array}$ \\
\hline 15 & $\begin{array}{l}\text { Móveis RTA: armários, } \\
\text { fruteiras, escritórios e } \\
\text { racks }\end{array}$ & Médio e Baixo & $\begin{array}{l}\text { América Central e } \\
\text { EUA }\end{array}$ & Sim & $\begin{array}{l}\text { Sim } \\
\text { ISO }\end{array}$ & $\begin{array}{l}\text { Alto. Grande capacidade produtiva, } \\
\text { alta qualidade fabril e financeira. } \\
\text { Expo=8\%. }\end{array}$ \\
\hline 16 & $\begin{array}{l}\text { Bares, cristaleiras, } \\
\text { estantes, salas de jantar } \\
\text { e racks }\end{array}$ & Médio & $\begin{array}{l}\text { América Central e } \\
\text { do Sul }\end{array}$ & Sim & Não & $\begin{array}{l}\text { Médio. Boa fábrica, organização e } \\
\text { showroom, mas baixa capacidade } \\
\text { produtiva. Expo=5\%. }\end{array}$ \\
\hline 17 & $\begin{array}{l}\text { Mesas, estantes, racks } e \\
\text { home theaters }\end{array}$ & Alto & Não exporta & Não & Não & $\begin{array}{l}\text { Alto. Excelente fábrica com grande } \\
\text { capacidade de produção e financeira. } \\
\text { Expo }=0 \% \text {. }\end{array}$ \\
\hline
\end{tabular}

Nota. Fonte: SINDMÓVEIS (L. B. Ramos, comunicação pessoal, 10 de agosto de 2013).

${ }^{1}$ Associado. ${ }^{2}$ Posicionamento de mercado (público-alvo). ${ }^{3}$ Lista de Preços em US\$. ${ }^{4}$ Certificado. 
O assessor de comércio exterior da entidade ressalta que o trabalho foi desenvolvido durante um mês, envolvendo visitas e entrevistas em cada uma das empresas associadas. Para que todos pudessem entender os critérios adotados para a coleta e tratamento das informações apresentadas, o diretor de comércio exterior da entidade fez uma pequena explanação sobre o questionamento feito em cada item e como o mesmo foi avaliado, o que pode ser observado a seguir:

Produto: quais os tipos de móveis produzidos pelo associado?

Posicionamento: qual o segmento de mercado ou público-alvo que o associado procura atender com seus móveis? Esse critério foi dividido em: Alto (classe A); Médio Alto (classes A e B); Médio (classes B e C); Médio Baixo (classe C); e Baixo (classes C e D ou linha econômica).

Mercados: caso o associado já exportasse, quais mercados são atendidos no exterior?

Preços (\$): o associado já possui lista de preços de exportação em dólares? Definir preços na exportação em moeda estrangeira é um grande problema, de acordo com o diretor de comércio exterior, para quem nunca exportou.

Certificações: o associado possui alguma certificação? Qual? Possuir certificações de qualidade e/ou origem da madeira e dos produtos pode ser uma exigência importante em muitos mercados no exterior, principalmente para produtos de alto padrão.

Potencial: buscou-se analisar a capacidade produtiva e financeira para iniciar ou expandir a atividade de exportação do associado. Um projeto de prospecção de mercados no exterior demanda uma disponibilidade significativa de recursos financeiros e produtivos da empresa. Segundo o diretor de comércio exterior, caso a empresa esteja com dificuldades financeiras no Brasil, não tenha capacidade ociosa para atender a pedidos no exterior ou, ainda, apresente uma tecnologia fabril defasada para exigências impostas em mercados internacionais, seria difícil para esse associado desenvolver a atividade exportadora. Após o levantamento de dados nas empresas, o diretor e o assistente de comércio exterior criaram três perfis de potencial exportador: alto, médio e baixo. Para complementar, procurou-se identificar o percentual do faturamento mensal da empresa que já é proveniente da exportação, representado como Expo=\% no quadro.

\section{O Fim da Reunião e as Perspectivas para a AIMOB}

Ao término da reunião na sede da AIMOB, vários questionamentos e, principalmente, a necessidade de desenvolver e implementar ações práticas que dessem conta da discussão em torno das exportações da AIMOB vieram à tona. Os presentes questionaram se, de fato, há oportunidades para todos os associados na exportação de móveis ou apenas para os já iniciados. A preocupação dos gestores que participaram da reunião era de que não houvesse ganhos significativos que justificassem o investimento de recursos da AIMOB e dos associados nesse empreendimento.

Ainda, quais seriam as principais dificuldades ou barreiras internas que, como associação e individualmente como empresa, os gestores da AIMOB deveriam enfrentar? Quais elementos representariam vantagens competitivas para as empresas atuarem como associação no exterior? Quais programas ou mecanismos de apoio à exportação existentes seriam mais adequados aos associados da AIMOB, dado o perfil e estágio de envolvimento com a exportação de cada membro? Por fim, quais seriam as iniciativas e passos necessários para a AIMOB desenvolver efetivamente mercados externos para seus associados?

Todas essas questões começaram a ser registradas em ata da reunião, mas o mais importante era o sentimento entre os participantes do encontro de que algo precisaria ser feito e com certa urgência. $O$ presidente da entidade e alguns associados tinham a certeza de que o futuro da associação passava pelo sucesso da atividade exportadora da AIMOB, inserindo o maior número de empresas associadas no exterior. 


\title{
Notas de Ensino
}

\section{Resumo}

Este caso para ensino relata o desafio estratégico colocado aos diretores da AIMOB, uma associação de 17 PMEs brasileiras fabricantes de móveis. Para garantir o crescimento da entidade e seus associados, é urgente a discussão sobre estratégias que a AIMOB poderá promover para a exportação de móveis. Assim, a partir dos dados apresentados sobre a entidade, seus associados e sobre o mercado internacional de móveis, o leitor é convidado a desenvolver alternativas para a internacionalização da entidade e seus associados. O caso proposto baseia-se no caso concreto de uma entidade brasileira, trazendo as variáveis internas e de mercado necessárias à análise e à proposição de estratégias de inserção internacional. Os objetivos educacionais pretendidos são: (a) analisar os recursos, motivadores e fragilidades da entidade e de seus associados para um projeto de internacionalização; (b) discutir ações individuais e colaborativas para a inserção internacional de móveis brasileiros no exterior; e (c) identificar lacunas onde programas de governo e outras entidades possam auxiliar no processo de internacionalização da entidade e associados. O presente caso de ensino pode ser usado em cursos de graduação e pós-graduação, stricto e lato sensu, em temas ligados a negócios internacionais, comércio exterior e marketing internacional.

Palavras-chave: caso de ensino; internacionalização de PMEs; exportação de móveis; redes de colaboração; indústria moveleira.

\begin{abstract}
This teaching case relates the strategic challenge faced by AIMOB executives, an association of 17 SME Brazilian furniture manufacturers. To ensure member and organization growth, there is an urgent discussion of possible AIMOB strategies that can promote furniture exports. So, from the data presented during an AIMOB meeting about the association and its members, as well as about the international furniture market, the reader is invited to develop alternatives for the internationalization of the entity and its members. The case proposed here is based on a concrete case of a Brazilian entity, including the internal and market variables needed to analyze and to propose international insertion strategies. The educational goals intended by this case are: (a) to analyze the resources, motivation and weaknesses of the entity and its associates for an internationalization project; (b) to discuss individual and collaborative actions for the international insertion of Brazilian furniture abroad; and (c) to identify gaps where government programs and other organizations can assist the internationalization process of the entity and its associates. This teaching case can be used in undergraduate and graduate programs in classes related to international business, foreign trade and international marketing.
\end{abstract}

Key words: teaching case; SME internationalization; furniture exports; networks; furniture industry.

\section{Objetivos educacionais e utilização recomendada do caso}

O presente caso para ensino tem o objetivo pedagógico precípuo de estimular a discussão sobre as possibilidades, motivações e dificuldades na internacionalização de pequenas e médias empresas (PMEs) brasileiras. O caso também promove a reflexão sobre as vantagens e desafios de atuação em redes colaborativas para a inserção internacional de PMEs de países emergentes.

Entende-se que o professor que aplicará o presente caso de ensino perceberá que os alunos, possivelmente, se não intervier, irão fazer muitas sugestões, sem recorrer à teoria, gerando uma discussão um tanto desestruturada e caótica. Recomenda-se estimular essa dinâmica e, quando os alunos estiverem confusos, o professor poderia entrar com as questões pontuais, chamando a atenção para os vários aspectos presentes e mostrando que a teoria pode ajudar, em situações como essa, a estruturar uma abordagem. 
O caso de ensino apresentado pode ser aplicado para turmas de pós-graduação em programas de MBA, em disciplinas ligadas a negócios internacionais ou estratégias de internacionalização. Em turmas de graduação, recomenda-se aplicar o caso para alunos que estejam mais ao final de cursos como Comércio Exterior e Relações Internacionais e que estejam familiarizados com temas de marketing, estratégia e planos de negócios. Dessa forma, algumas sugestões de questões e de dinâmicas são propostas a seguir.

\section{Fonte dos dados}

O caso AIMOB traz uma experiência real de uma associação de PMEs moveleiras do Estado do Rio Grande do Sul. Contudo, os nomes da entidade e dos gestores envolvidos foram alterados por solicitação dos seus diretores, mas os dados apresentados são fidedignos.

A coleta de dados para a construção do presente caso para ensino deu-se por meio de entrevistas em profundidade com os gestores da associação e com todos os sócios e proprietários das empresas associadas. Além disso, foi realizada extensa análise documental em atas das reuniões e relatórios internos da entidade, bem como a análise dos sites da organização e de seus associados, pesquisa documental em instituições como BNDES, APEX e SINDMÓVEIS.

Por fim, cabe destacar que se realizou observação direta na entidade, pois a coleta e análise dos dados foram realizadas ao longo do trabalho de consultoria dos autores do caso, que participaram de várias atividades na associação.

\section{Sugestão de questões para discussão}

É apresentando, na sequência, um conjunto de indagações que podem ser direcionadas para promover a discussão do caso em sala de aula. Destaca-se, no entanto, que as possibilidades de temas e reflexões que o caso sugere não se encerram aqui, sendo que o docente poderá explorar outras questões relativas à internacionalização de PMEs brasileiras e à atuação em redes de colaboração.

1. Quais as razões/motivações para a AIMOB e seus associados explorarem mercados externos? Quais os riscos apresentados à entidade e seus associados por atuarem apenas no mercado doméstico? As motivações e os riscos são os mesmos para todos os associados? Por quê?

2. Quais pontos fortes ou vantagens competitivas a AIMOB oferece para os seus associados atuarem no exterior? Todos os associados são beneficiados pelos mesmos pontos fortes e vantagens? Por quê?

3. Quais as fragilidades ou os pontos fracos que a atuação como associação da AIMOB apresenta para seus associados na exportação?

4. Quais oportunidades podem ser desenvolvidas pelos associados da AIMOB no mercado internacional? Nesse sentido, os exigentes importadores europeus de móveis representam uma oportunidade ou uma ameaça para a atuação internacional da indústria moveleira brasileira?

5. Como as empresas integrantes da AIMOB podem lidar com a concorrência chinesa e europeia no mercado de móveis mundial?

6. De quais programas ou mecanismos de apoio à exportação, patrocinados pelo governo e outras entidades, a AIMOB e seus associados poderiam lançar mão para promover a exportação? Esses instrumentos de apoio atendem a todos associados? Se não, a quais?

7. Como a entidade pode lidar com a grande diversidade encontrada no perfil de seus associados, no que diz respeito aos produtos, seus recursos e à experiência internacional de cada membro?

8. Quais estratégias de comunicação a entidade poderia implementar para promover os produtos de seus associados e a própria entidade no exterior? 
9. Como a experiência internacional de algumas empresas associadas e a sua rede de relacionamentos no exterior podem ser aproveitadas pelas demais associadas da AIMOB que ainda não exportam?

\section{Análise do Caso AIMOB}

A leitura do caso AIMOB sugere várias possibilidades de interpretação e uso como ferramenta didático-pedagógica para utilização em sala de aula na formação de gestores que estão promovendo a internacionalização de PMEs em redes. Dessa forma, serão discutidas cinco possibilidades de análise que podem ser feitas a partir do caso, bem como algumas sugestões de dinâmicas para o seu desenvolvimento. São elas: (a) identificar os motivadores para a internacionalização; (b) análise SWOT para um International Business Plan; (c) estratégias para a internacionalização de PMEs; (d) análise dos mecanismos de apoio à exportação mais adequados ao estágio exportador das empresas; e (e) possibilidades e limitações na atuação internacional em redes de relacionamento e colaboração.

Uma primeira abordagem diz respeito a identificar os motivadores para a internacionalização do grupo de indústrias moveleiras. A motivação para internacionalização de uma empresa deveria estar associada a fatores que levassem à alavancagem estratégica da empresa, ou seja, que gerassem uma vantagem competitiva sustentável para ela. É possível chamar essas motivações de pró-ativas ou motivações que buscam o crescimento e a perenidade da empresa de maneira lucrativa. Alguns exemplos de motivação pró-ativa para a internacionalização de uma empresa são: adquirir tecnologia no exterior por obsolescência e escassez de recursos locais; estabelecer parcerias com fornecedores, clientes e concorrentes; auxiliar a necessidade de crescimento; reduzir a sazonalidade na produção; reduzir riscos de mercado; melhorar a imagem da empresa; adquirir experiência gerencial e operacional, entre outros.

As motivações pró-ativas proporcionam um olhar de longo prazo para a internacionalização de uma empresa, ou seja, geram a reflexão necessária para a escolha mais adequada dos mercados no exterior, parceiros, formas e estratégias de acesso.

Já as motivações que provêm de situações momentâneas de mercado muitas vezes não geram alavancagem estratégica para a empresa. Essas motivações, conhecidas como reativas, dirigem para uma internacionalização forçada, ou seja, para que a empresa apenas sobreviva a uma situação de turbulência no mercado doméstico. Assim, uma empresa não conseguiria construir um planejamento estratégico de longo prazo para sua internacionalização com base em motivações reativas, pois dificilmente conseguirá sustentar tal estratégia. Algumas motivações reativas para a internacionalização de uma empresa são: quedas nas vendas no mercado doméstico e excesso de capacidade ociosa; pressão imposta pelos concorrentes; oscilação na taxa de câmbio; imposição de clientes e fornecedores.

Cabe salientar que, especialmente no caso brasileiro, muitos gestores acabam sendo forçados a propor a internacionalização de suas atividades por uma necessidade meramente reativa, como é o caso das fortes oscilações da taxa de câmbio e o desaquecimento do mercado doméstico.

A análise SWOT, por outro lado, ajudaria a entidade a identificar quais os pontos fortes e fracos da associação, principalmente no que diz respeito aos ganhos e fragilidades da atuação de maneira colaborativa. A partir da análise interna (pontos fortes e pontos fracos), bem como da análise externa (oportunidades e ameaças de mercado), seria possível o estabelecimento de estratégias mais adequadas para a AIMOB lidar com o desafio da internacionalização de seus associados. De maneira complementar, poderia ser indicada a pesquisa em dados secundários (desk research) sobre o cenário internacional recente da indústria moveleira. Assim, o caso pode ser empregado na disciplina de Marketing Internacional na análise do ambiente internacional de negócios e na decisão do Mix marketing (4 Ps) para mercados externos. A Tabela 5 traz uma síntese de uma análise SWOT da AIMOB. 
Tabela 5

\section{Matriz SWOT para Projeto Internacional da AIMOB}

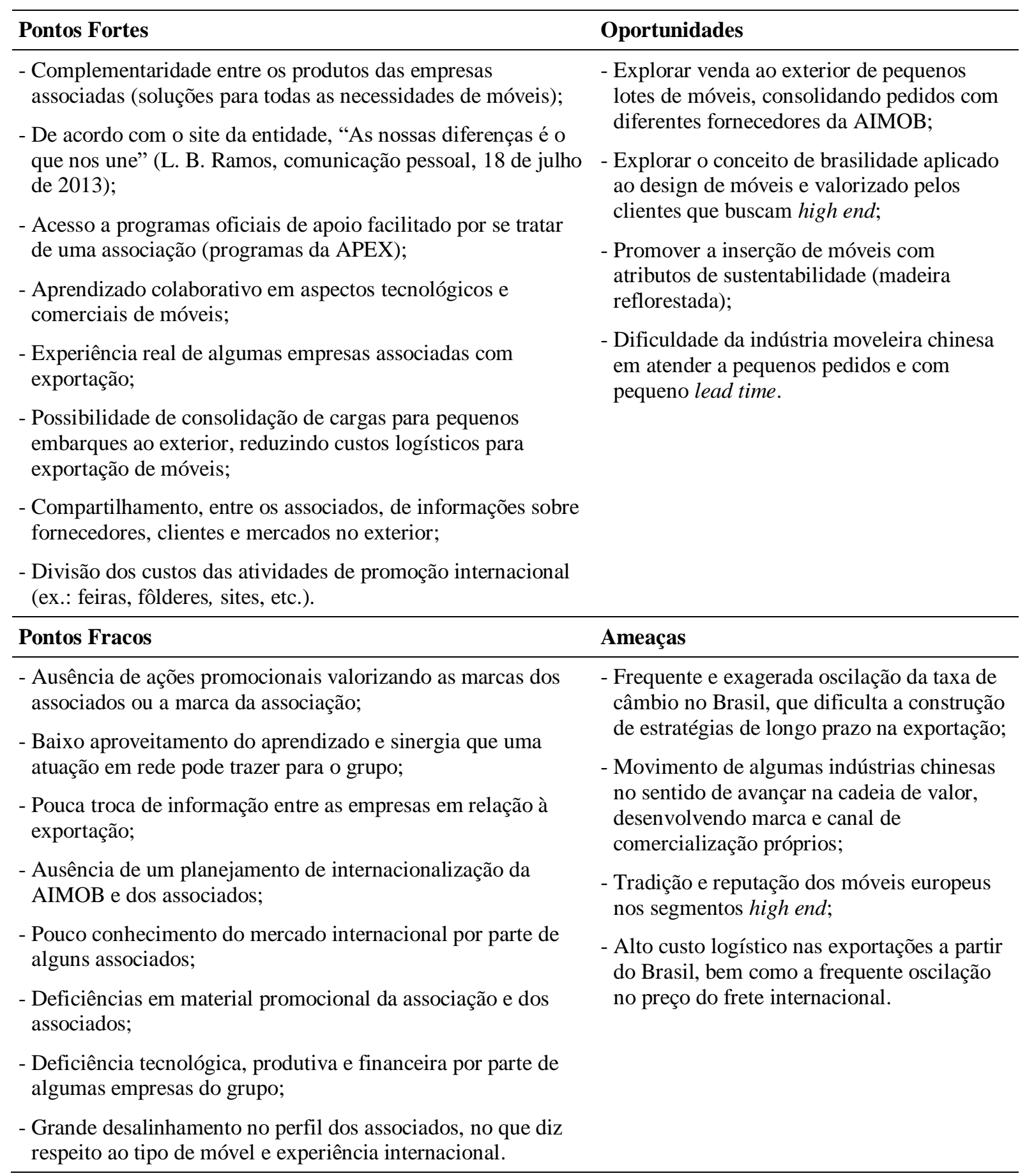

Nota. Fonte: SINDMÓVEIS (L. B. Ramos, comunicação pessoal, 10 de agosto de 2013).

Ao se discutir o processo de internacionalização de PMEs, uma das correntes teóricas mais consagradas ficou conhecida como o Modelo de Uppsala ou Modelo-U, na década de 70, quando um grupo de pesquisadores (Johanson \& Vahlne, 1977; Johanson \& Wiedersheim-Paul, 1975) buscou analisar o processo de internacionalização de firmas suecas manufatureiras. De acordo com os pressupostos da Escola de Uppsala, o processo de internacionalização decorre de um conjunto de decisões de caráter incremental. Para Johanson e Vahlne (1977), o envolvimento com o mercado externo 
aumenta na medida em que ocorre a redução da incerteza e da distância psíquica para com mercados no exterior, pelo ganho de experiência e aprendizagem dos gestores.

Entretanto, Andersen (1993) distinguiu outro modelo de estágios também relacionado ao modeloU, que ficou conhecido como o Modelo de Inovação ou modelo-I. No modelo-I, ou I-model, o processo de internacionalização é uma decisão inovadora dos gestores, que se desenvolve por meio de estágios. A visão acadêmica corrente naqueles estudos sugeria que o envolvimento em relação à exportação é um processo sequencial de aprendizado que se desenrola em estágios (Bilkey \& Tesar, 1977; Cavusgil, 1980; Kotabe \& Czinkota, 1992; Leonidou \& Katsikeas, 1996; Reid, 1983). O aprendizado dos gestores durante o processo é um elemento importante deste esquema teórico e a natureza lenta desse processo deve-se à aversão ao risco e à falta de conhecimento (Bilkey \& Tesar, 1977).

Cavusgil (1980) sugere que as empresas tendem a se internacionalizar sem uma análise racional anterior. Essa internacionalização é um processo gradual que avança em estágios de caráter incremental em um período relativamente longo de tempo, no qual cada estágio traz maior comprometimento de recursos e de aptidões dos gestores da organização. A Tabela 6, a seguir, apresenta uma compilação dos estágios propostos por Cavusgil (1980), porém, enfatizando variáveis operacionais adaptadas ao contexto exportador atual.

Tabela 6

Envolvimento Exportador por Estágios

\begin{tabular}{cccccc}
\hline $\begin{array}{c}\text { ESTÁGIOS NA } \\
\text { EXPORTAÇÃO }\end{array}$ & $\begin{array}{c}\text { RAZÃO } \\
\text { EXPO/VENDA }\end{array}$ & $\begin{array}{c}\text { FOCO } \\
\text { ESTRATÉGICO }\end{array}$ & MERCADOS & PRODUTO & $\begin{array}{c}\text { EMBARQUES AO } \\
\text { EXTERIOR }\end{array}$ \\
\hline $\begin{array}{c}\text { MERCADO } \\
\text { DOMÉSTICO }\end{array}$ & 0 & Doméstico & Doméstico & $\begin{array}{c}\text { Local e } \\
\text { padronizado }\end{array}$ & Não há \\
\hline $\begin{array}{c}\text { PRÉ- } \\
\text { EXPORTAÇÃO }\end{array}$ & Próximo a zero & $\begin{array}{c}\text { Doméstico e } \\
\text { oportunista }\end{array}$ & $\begin{array}{c}\text { Doméstico e } \\
\text { próximos }\end{array}$ & $\begin{array}{c}\text { Local e baixa } \\
\text { adaptação }\end{array}$ & $\begin{array}{c}\text { Esporádicos, baixa } \\
\text { regularidade }\end{array}$ \\
\hline $\begin{array}{c}\text { ENVOLVIMENTO } \\
\text { EXPERIMENTAL }\end{array}$ & 0 a 9\% & $\begin{array}{c}\text { Doméstico e } \\
\text { intencional }\end{array}$ & $\begin{array}{c}\text { Doméstico e } \\
\text { próximos }\end{array}$ & $\begin{array}{c}\text { Local e } \\
\text { adaptado }\end{array}$ & $\begin{array}{c}\text { Mensais, média } \\
\text { regularidade }\end{array}$ \\
\hline $\begin{array}{c}\text { ENVOLVIMENTO } \\
\text { ATIVO }\end{array}$ & 10 e 39\% & Internacional & Internacionais & Internacional & $\begin{array}{c}\text { Semanais, diários, } \\
\text { alta regularidade }\end{array}$ \\
\hline $\begin{array}{c}\text { ENVOLVIMENTO } \\
\text { ABSOLUTO }\end{array}$ & $40 \%$ ou mais & Global & Global & Global & $\begin{array}{c}\text { Diários, } \\
\text { alta regularidade }\end{array}$ \\
\hline
\end{tabular}

Nota. Fonte: Adaptado de Cavusgil, S. (1980). On the internationalization process of firms (p. 275). European Research, 8(6), 273-281.

Atualmente, vários estudos indicam que o processo de internacionalização das pequenas e médias empresas, compreendido por muito tempo como gradual e por estágios, mudou e acelerou (Knight \& Cavusgil, 1996, 2005; Moen \& Servais, 2002). De forma geral, percebe-se a existência das PMEs nascidas globais em vários países (Oviatt \& McDougall, 1994; Rennie, 1993), mesmo naqueles em desenvolvimento (Dib, Rocha, \& Silva, 2010; Hagen \& Zuchela, 2014; Kyvik, Saris, Bonet, \& Felício, 2013; Rialp, Rialp, \& Knight, 2005).

Contudo, não parece ser esse o caso das empresas da AIMOB, ou seja, de rápida internacionalização. Assim, uma dinâmica interessante seria propor aos alunos que separassem as 17 empresas associadas de acordo com o seu grau de envolvimento com a exportação, podendo usar o quadro da Tabela 6 como sugestão de classificação. A partir disso, ações poderiam ser sugeridas para os diferentes tipos de associados em diferentes estágios de maturidade na exportação. O objetivo seria fazer com que as PMEs associadas, a curto ou longo prazo, estivessem em estágios mais próximos de desenvolvimento internacional. 
Outra possibilidade de desafio aos alunos seria, a partir da classificação das empresas pelos seus estágios de envolvimento com a exportação, pesquisar mecanismos de apoio oficiais à exportação mais adequados a cada grupo de associados. Os programas e atividades oficiais de promoção às exportações podem ser classificados de duas formas, de acordo com Kotabe e Czinkota (1992, p. 639):

programas de serviços de exportação (por exemplo, seminários para exportadores potenciais, consultoria a exportadores, manuais sobre como exportar e financiamento para exportação); e programas de desenvolvimento de mercado (por exemplo, programas voltados à disseminação de indicações de compradores potenciais às empresas locais, ao auxílio à participação em feiras internacionais, análise de mercados e informativos sobre exportação).

Ainda, a assistência oficial à exportação pode variar dependendo se a intenção é fornecer conhecimento objetivo ou experiencial. Os programas que conferem conhecimento objetivo aos exportadores são aqueles do tipo how to do, seminários, workshops; já os que dão conhecimento experiencial são os encontros com importadores, as feiras internacionais, as missões comerciais e os financiamentos à exportação (Crick \& Czinkota, 1995; Gençtürk \& Kotabe, 2001; Singer \& Czinkota, 1994).

No entanto, a despeito da eficácia de alguns programas de apoio à exportação, há um modelo causal que emerge da literatura e que liga, mesmo que imperfeitamente, os serviços e agências de promoção e apoio às exportações com a performance internacional das empresas que os utilizam (Gençtürk \& Kotabe, 2001; Gillespie \& Riddle, 2004; Shamsuddoha \& Ali, 2006).

Para orientar o trabalho do docente e dos alunos, recomenda-se o uso de um quadro (Tabela 7) adaptado do trabalho de Seringhaus e Rosson (1990), que propõem uma adequação dos programas de apoio à exportação ao estágio de desenvolvimento da atividade de exportação da empresa.

Tabela 7

\section{A Relação do Estágio Exportador com o Programa de Apoio à Exportação}

\begin{tabular}{ll}
\hline Estágio exportador & Objetivo do programa de apoio \\
\hline $\begin{array}{l}\text { Empresa totalmente desinteressada na } \\
\text { exportação }\end{array}$ & $\begin{array}{l}\text { Aumentar a percepção sobre os benefícios do mercado } \\
\text { externo. }\end{array}$ \\
\hline $\begin{array}{l}\text { Empresa parcialmente interessada na } \\
\text { exportação }\end{array}$ & $\begin{array}{l}\text { Aumentar a percepção dos benefícios da exportação e oferecer } \\
\text { informações sobre procedimentos para exportar. }\end{array}$ \\
\hline Empresa em fase de exportação exploratória & $\begin{array}{l}\text { Tornar a exportação mais lucrativa e fornecer informações e } \\
\text { assistência prática. }\end{array}$ \\
\hline Empresa exportadora em fase experimental & $\begin{array}{l}\text { Estimular a exploração constante do mercado externo, fornecer } \\
\text { assistência global e auxiliar na adaptação do produto. }\end{array}$ \\
\hline Pequeno exportador experiente & $\begin{array}{l}\text { Tornar mais lucrativa a atividade de exportação, fornecer } \\
\text { assistência global e prover financiamento. }\end{array}$ \\
\hline Grande exportador experiente & $\begin{array}{l}\text { Facilitar o atendimento ao cliente externo, fornecendo } \\
\text { assistência global. }\end{array}$ \\
\hline
\end{tabular}

Nota. Fonte: Adaptado de Seringhaus, F. H. R., \& Rosson, P. J. (1990). Government export promotion: a global perspective (p. 31, tradução nossa). New York: Routledge.

Por fim, parece já estar consolidado na literatura de negócios internacionais o fato de que PMEs, pelas suas restrições de recursos, sofrem mais em seu processo de internacionalização do que grandes empresas. Nesse sentido, a atuação internacional em redes de relacionamento e colaboração pode auxiliar as PMEs a vencerem, em conjunto, gaps competitivos para a internacionalização, o que isoladamente essas empresas não conseguiriam. O caso de ensino da AIMOB procura explorar, também, as vantagens e limitações de uma atuação em rede de colaboração para a internacionalização. 
O termo network no campo de negócios internacionais procura designar um conjunto de atores interconectados ou, ainda, uma rede pessoal de conexões e relacionamentos que buscam favorecer a ação de uma empresa ou pessoa (Zhou, Wu, \& Luo, 2007). Welch e Welch (1996) argumentam que a criação de redes para as operações internacionais pode representar um ativo estratégico importante, principalmente para PMEs que sofrem maiores restrições ao longo do seu processo de internacionalização.

Para Johanson e Vahlne (2009), os relacionamentos, ou a falta deles, podem determinar o sucesso internacional de PMEs, ou seja, para Vahlne e Johanson (2013), o Modelo de Uppsala de internacionalização gradual precisa ser revisto, não se tratando, agora, apenas do processo de internacionalização como um processo isolado. Para eles, os relacionamentos construídos no mercado doméstico e internacional representam um grande ativo para alavancar a internacionalização das PMEs.

Do ponto de vista didático-pedagógico, uma boa análise do caso pode sugerir algumas oportunidades ou vantagens da atuação em rede para a internacionalização de empresa, como os elementos apontados nos Pontos Fortes da análise SWOT da AIMOB. Por outro lado, nota-se que há um sentimento de falta de alinhamento no perfil e objetivos quanto à internacionalização das empresas integrantes da associação. Dessa maneira, outra abordagem seria buscar identificar as limitações ou desvantagens da atuação em redes, como a possibilidade de alguns associados poderem se beneficiar mais das ações da entidade do que outros, por estarem em um estágio mais avançado de comprometimento exportador. Ainda, pode haver o abandono da rede de colaboração quando o gestor percebe que não há mais benefícios em permanecer na associação.

\section{Lista de Termos}

Aglomerado - Painéis de madeira reconstituída com partículas de pinus e eucalipto e resina sintética.

Home theaters - Estantes de grandes dimensões para equipamentos de áudio e vídeo.

Living - Área de convívio destinada a móveis como sofás, aparadores, entre outros.

MDF - Fibras de Média Densidade (medium-density fiberboard) produzidas a partir de partículas de madeira prensada.

Móveis retilíneos - Móveis lisos com desenhos simples de linhas retas.

Móveis seriados - Móveis de produção em série em grandes linhas fabris.

Público-alvo baixo - Consumidores das classes D e E (mercado low end).

Público-alvo médio - Consumidores da classe $\mathrm{C}$ e inferior de $\mathrm{B}$ (mercado middle end).

Público-alvo alto - Consumidores da classe A e superior da classe B (mercado high end).

Racks - Pequenas estantes para equipamentos de áudio e vídeo.

RTA - Ready to assemble, que são móveis retilíneos de pequeno porte vendidos desmontados e que o cliente mesmo monta em sua casa. 


\section{Referências}

Agência Brasileira de Promoção de Exportações e Investimento. (2012). Perfil exportador do setor brasileiro de móveis. Recuperado de http://www.apexbrasil.com.br/Content/imagens/581b6489f158-45fd-afec-70173efadeec.pdf

Andersen, O. (1993). On the internationalization process of firms: a critical analysis. Journal of International Business Studies, 24(2), 209-231. http://dx.doi.org/10.1057/palgrave.jibs.8490230

Bilkey, W. J., \& Tesar, G. (1977). The export behaviour of small-sized Wisconsin manufacturing firms. $\begin{array}{lllll}\text { Journal of International Business } & \text { Studies, } & \text { 8(1), } & \text { 93-98. }\end{array}$ http://dx.doi.org/10.1057/palgrave.jibs.8490783

Cavusgil, S. (1980). On the internationalization process of firms. European Research, 8(6), 273-281.

Crick, D., \& Czinkota, M. R. (1995). Export assistance: another look at whether we are supporting the best programmes. International Marketing Review, 12(3), 61-72. http://dx.doi.org/10.1108/02651339510091708

Dib, L. A., Rocha, A., \& Silva, J. F. (2010). The internationalization process of Brazilian software firms and the born global phenomenon: examining firm, network, and entrepreneur variables. Journal of International Entrepreneurship, 8(3), 233-253. http://dx.doi.org/10.1007/s10843-010-0044-z

Gençtürk, E. F., \& Kotabe, M. (2001). The effect of export assistance program usage on export performance: a contingency explanation. Journal of International Marketing, 9(2), 51-71. http://dx.doi.org/ 10.1509/jimk.9.2.51.19886

Gillespie, K., \& Riddle, L. (2004). Export promotion organization emergence and development: a call to research. International Marketing Review, 21(4), 462-473. http://dx.doi.org/10.1108/02651330410547144

Hagen, B., \& Zucchella, A. (2014). Born global or born to run? The long-term growth of born global firms. Management International Review, 54(4), 497-525. http://dx.doi.org/10.1007/s11575-0140214-7

Johanson, J., \& Vahlne, J. E. (1977). The internalization process of the firm - a model of knowledge development and increasing foreign market commitments. Journal of International Business Studies, 8(1), 23-32. http://dx.doi.org/10.1057/palgrave.jibs.8490676

Johanson, J., \& Vahlne, J. E. (2009). The Uppsala internationalization process model revisited: from liability of foreignness to liability of outsidership. Journal of International Business Studies, 40(9), 1411-1431. http://dx.doi.org/10.1057/jibs.2009.24

Johanson, J., \& Wiedersheim, P. (1975). The internationalization of the firm - four swedish cases. Journal of Management Studies, 12(3), 305-323. http://dx.doi.org/10.1111/j.14676486.1975.tb00514.x

Knight, G. A., \& Cavusgil, S. T. (1996). The born global firm: a challenge to traditional internationalization theory. Advances in International Marketing, 8, 11-26.

Knight, G. A., \& Cavusgil, S. T. (2005). A taxonomy of born-global firms. Management International Review, 45(3), 15-35.

Kotabe, M., \& Czinkota, M. R. (1992). State government promotion of manufacturing exports: a gap analysis. Journal of International Business Studies, 23(4), 637-658. http://dx.doi.org/10.1057/palgrave.jibs.8490281 
Kyvik, O., Saris, W., Bonet, E., \& Felício, J. A. (2013). The internationalization of small firms: the relationship between the globalmindset and firms' internationalization behavior. Journal of International Entrepreneurship, 11(2), 172-195. http://dx.doi.org/10.1007/s10843-013-0105-1

Leonidou, L., \& Katsikeas, C. S. (1996). The export development process: an integrative review of empirical models. Journal of International Business Studies, 27(3), 517-551. http://dx.doi.org/10.1057/palgrave.jibs.8490846

Ministério do Desenvolvimento Indústria e Comércio Exterior. (2014). Estatísticas de comércio exterior. Recuperado de http://www.mdic.gov.br/index.php/comercio-exterior/estatisticas-decomercio-exterior

Moen, O., \& Servais, P. (2002). Born global or gradual global? Examining the export behavior of small and medium-sized enterprises. Journal of International Marketing, 10(3), 49-72. http://dx.doi.org/10.1509/jimk.10.3.49.19540

Oviatt, B. M., \& McDougall, P. P. (1994). Toward a theory of international new ventures. Journal of International Business Studies, 25(1), 45-64. http://dx.doi.org/10.1057/palgrave.jibs.8490193

Reid, S. D. (1983). Firm internationalization: transaction costs \& strategic choice. International Marketing Review, 1(2), 44-56. http://dx.doi.org/10.1108/eb008251

Rennie, M. W. (1993). Global competitiveness: born global. The Mckinsey Quarterly, 4, 45-52.

Rialp, A., Rialp, J., \& Knight, G. (2005). The phenomenom of international new ventures, global startups, and born globals: what do we know after a decade (1993-2002) of scientific enquiry? International Business Review, 14(2), 147-166. http://dx.doi.org/10.1016/j.ibusrev.2004.04.006

Rosa, S. E. S. da, Correa, A. R., Lemos, M. L. F., \& Barroso, D. V. (2007). O setor de móveis na atualidade: uma análise preliminar. BNDES Setorial, (25), 65-106. Recuperado de https://web.bndes.gov.br/bib/jspui/handle/1408/2469.pdf

Seringhaus, F. H. R., \& Rosson, P. J. (1990). Government export promotion: a global perspective. New York: Routledge.

Shamsuddoha, A. K., \& Ali, M. Y. (2006). Mediated effects of export promotion programs on firm export performance. Asia Pacific Journal of Marketing and Logistics, 18(2), 93-110. http://dx.doi.org/10.1108/13555850610658255

Singer, T. O., \& Czinkota, M. R. (1994). Factors associated with effective use of export assistance. Journal of International Marketing, 2(1), 53-71. Retrieved from http://www.jstor.org/stable/25048530

Vahlne, J. E., \& Johanson, J. (2013). The Uppsala model on evolution of the multinational business enterprise - from internalization to coordination of networks. International Marketing Review, 30(3), 189-210. http://dx.doi.org/10.1108.02651331311321963

Welch, D. E., \& Welch L. S. (1996). The internationalization process and networks: a strategic management perspective. Journal of International Marketing, 4(3), 11-28. http://dx.doi.org/10.4135/9781446261514

Zhou, L., Wu, W.-P., \& Luo, X. (2007). Internationalization and the performance of born-global smes: the mediating role of social networks. Journal of International Business Studies, 38(4), 673-690. http://dx.doi.org/10.1057/palgrave.jibs.8400282 


\section{Dados dos Autores}

Marcelo André Machado

Av. Luiz Manoel Gonzaga, 744, Três Figueiras, 90470-280, Porto Alegre, RS, Brasil. E-mail: mmachado@unisinos.br Ivan Lapuente Garrido

Av. Unisinos, 950, Cristo Rei, 93022-000, São Leopoldo, RS, Brasil. E-mail: igarrido@ unisinos.br 